\title{
The association between dietary protein intake, energy intake and physical frailty: results from the Rotterdam Study
}

\author{
Josje D. Schoufour ${ }^{1,2 *}$, Oscar H. Franco ${ }^{1}$, Jessica C. Kiefte-de Jong $^{1,3}$, Katerina Trajanoska ${ }^{1,2}$, \\ Bruno Stricker $^{1}$, Guy Brusselle ${ }^{1,4,5}$, Fernando Rivadeneira ${ }^{1,2}$, Lies Lahousse ${ }^{1,4}$ and Trudy Voortman ${ }^{1}$ \\ ${ }^{1}$ Department of Epidemiology, Erasmus MC, 3000 CA Rotterdam, The Netherlands \\ ${ }^{2}$ Department of Internal Medicine, Erasmus MC, 3000 CA Rotterdam, The Netherlands \\ ${ }^{3}$ Leiden University College, 2595 DG The Hague, The Netherlands \\ ${ }^{4}$ Department of Respiratory Medicine, Ghent University Hospital, B-9000 Ghent, Belgium \\ ${ }^{5}$ Department of Respiratory Medicine, Erasmus MC, 3000 CA Rotterdam, The Netherlands \\ (Submitted 2 February 2018 - Final revision received 22 September 2018 - Accepted 29 October 2018 - First published online 9 January 2019)
}

\section{Abstract}

Sufficient protein intake has been suggested to be important for preventing physical frailty, but studies show conflicting results which may be explained because not all studies address protein source and intake of other macronutrients and total energy. Therefore, we studied 2504 subjects with data on diet and physical frailty, participating in a large population-based prospective cohort among subjects aged $45+$ years (the Rotterdam Study). Dietary intake was assessed with a FFQ. Frailty was defined according to the frailty phenotype as the presence of at least three out of the following five symptoms: weight loss, low physical activity, weakness, slowness and fatigue. We used multinomial logistic regression models to evaluate the independent association between protein intake and frailty using two methods: nutrient residual models and energy decomposition models. With every increase in $10 \mathrm{~g}$ total, plant or animal protein per $\mathrm{d}$, the odds to be frail were 1.06 ( $95 \% \mathrm{CI} 0.98$, $1 \cdot 15), 0 \cdot 87$ (95\% CI 0.71, 1.07) and 1.07 (95\% CI 0.99, 1.15), respectively, using the nutrient residual method. Using the energy partition model, we observed that the odds to be frail were lower with higher vegetable protein intake (OR per $418.4 \mathrm{~kJ}(100 \mathrm{kcal}): 0.61,95 \% \mathrm{CI} 0 \cdot 39,0 \cdot 97$ ), however, results disappeared when adjusting for physical activity. For energy intake from any source we observed that with every $418 \cdot 4 \mathrm{~kJ}$ (100 kcal) increase, the odds to be frail were 5\% lower (OR: 0.95, $95 \%$ CI 0.93, 0.97). Our results suggest that energy intake, but not protein specifically, is associated with less frailty. Considering other macronutrients, physical activity and diet quality seems to be essential for future studies on protein and frailty.

Key words: Physical frailty: Protein intake: Protein source: Energy adjustment: Population-based studies

In general, frailty is considered a state of increased vulnerability to stressor events, resulting in an increased risk of adverse health outcomes including disabilities, hospitalisation, institutionalisation and mortality ${ }^{(1,2)}$. The exact operationalisation and methods to measure frailty remain a matter of debate. One approach to conceptualise frailty is as a physical state using the frailty phenotype. The frailty phenotype defines frailty as a geriatric syndrome characterised as the presence of at least three out of the following five appearances: unintended weight loss, low physical activity, weakness, slowness and fatigue ${ }^{(3)}$. The frailty phenotype has been associated with low quality of life, poor cognitive functioning, hospitalisation, institutionalising, cachectic chronic diseases and mortality in older adults ${ }^{(4-8)}$. The estimated prevalence of physical frailty in communitydwelling older adults is around $10 \%$ in Western countries and the prevalence of pre-frailty (i.e. the presence of one or two of the five symptoms) is around $40 \%^{(9,10)}$. The high prevalence of the frailty syndrome and its severe impact on quality of life and health make the identification of risk factors and the development of preventive strategies essential.

A healthy diet has been proposed as one of the key factors to prevent or postpone frailty. Frail individuals have a lower intake of energy, protein, fibre and several micronutrients (e.g. vitamin D, vitamin $C$ and folate) compared with non-frail individuals ${ }^{(11-14)}$. Because physical frailty is highly influenced by loss of muscle mass and muscle strength (sarcopenia) ${ }^{(15,16)}$, the beneficial effect of protein intake has received particular attention. Dietary protein stimulates skeletal protein synthesis and insufficient supply can affect muscle integrity ${ }^{(17,18)}$. Nevertheless, although several, not all observational, studies report a beneficial association of protein intake with frailty ${ }^{(14,19-22)}$, inconsistencies could be caused by other factors that may influence the

Abbreviations: BW, body weight; MET, metabolic equivalent of task; RDA, recommended daily allowance; RS, Rotterdam Study.

* Corresponding author: J. D. Schoufour, fax +31 644363302, email j.schoufour@erasmusmc.nl; josje.schoufour@gmail.com 
association, such as physical activity ${ }^{(23-25)}$ and protein source (i.e. plant $v$. animal-derived $)^{(13,26)}$. It has been proposed that protein from animal food sources might be more protective because they are generally richer in essential amino acids such as leucine ${ }^{(27,28)}$. In addition, an association between higher protein intake and lower frailty could merely be caused by higher overall consumption of other nutrients or total energy intake: a dietary pattern high in proteins could represent a diet with more optimal overall nutrient intake and higher energy intake $^{(29,30)}$, which have both been associated with a lower frailty risk ${ }^{(12,31)}$. An overall low-energy intake could lead to undernutrition and muscle waste, leading to more frailty. More specifically, weakness and wasting of muscle mass due to chronic illness (cachexia) could also be associated with low total energy intake. Furthermore, emerging evidence suggest a non-linear association for protein, as protein intake may only be beneficial if levels above the recommended daily allowance (RDA) are consumed ${ }^{(32)}$. The RDA is based on the minimal daily requirement for protein resulting in a whole body net $\mathrm{N}$ balance of zero, currently estimated to be $0.8 \mathrm{~g} / \mathrm{kg}$ body weight (BW) for the general population ${ }^{(3,34)}$. The PROT-AGE Study Group suggests that older adults need a higher protein intake, in the range of $1.0-1.2 \mathrm{~g} / \mathrm{kg} \mathrm{BW}$, to maintain their muscle mass ${ }^{(35)}$. Therefore, it is important to consider the overall diet and macronutrient substitution effects when examining the association between protein intake and frailty.

To better understand the association between dietary protein consumption and physical frailty in the context of the overall diet, we aimed to examine the association between dietary protein consumption from different food sources (plant and animal derived) and frailty, using different methods to account for intake of total energy, other macronutrients and diet quality. We further aimed to evaluate whether the risk of being frail or pre-frail is lower in subjects consuming at least 0.8 or $1.2 \mathrm{~g} / \mathrm{kg}$ per BW of protein daily.

\section{Methods}

\section{Study design and participants}

This study was embedded in the Rotterdam Study (RS), an ongoing population-based cohort among middle-aged and older adults aged 45 years and over. Currently there are almost 15000 subjects participating in the RS who were included between 1990 and 2006. The first wave (RS-I) started in 1990 and comprised 7983 participants (out of 10215 invited), the second wave (RS-II) was established in the year 2000 and comprised 3011 participants (out of 4472 invitees) and the third wave (RS-III) started in the year 2006 and comprised 3936 participants (out of 6057 invited). Follow-up measurements were performed every 3-5 years. At each round, participants were interviewed at home and subsequently invited to the research centre for a comprehensive set of examinations. This study was conducted according to the guidelines laid down in the Declaration of Helsinki, and all procedures involving human subjects were approved by the Medical Ethics Committee of the Erasmus MC and by the Ministry of Health, Welfare and Sport of the Netherlands, implementing the Wet
Bevolkingsonderzoek: ERGO (Population Studies Act: Rotterdam Study). All participants provided written informed consent to participate in the study and to obtain information from their treating physicians. Details regarding the design, selection procedure and objectives are provided elsewhere ${ }^{(36)}$.

\section{Frailty phenotype}

Data on all components of frailty were assessed in the fifth round of RS-I (RS-I-5, $n$ 2147) and the third round of RS-II (RS-II-3, $n$ 1893). For the current study, we included all participants from these waves who had valid information on both dietary intake and frailty ( $n$ 2504, 62\%). Frailty was measured using the physical frailty phenotype developed by Fried et $a l .{ }^{(3)}$, which was previously applied to the RS participants ${ }^{(10)}$. This concept defines frailty according to five pre-defined symptoms: weight loss, low physical activity, weakness, slowness and fatigue. Individuals with three or more of these symptoms are defined as frail, those with one or two as pre-frail and those with none as non-frail. We defined weight loss as losing more than $5 \%$ of BW during the past half-year. A low physical activity level was described as spending $<1130 \mathrm{~kJ} /$ week $(<270 \mathrm{kcal} /$ week) for women and $<1602 \mathrm{~kJ} /$ week $(<383 \mathrm{kcal} /$ week $)$ for men on physical activity, estimated using a self-reported questionnaire including items on walking, cycling, sports, gardening, hobbies and housekeeping ${ }^{(3)}$. Weakness was defined as poor grip strength, estimated using a handgrip dynamometer. Poor grip strength was defined using cut-offs stratified according to sex and BMI, as defined by Fried et al. ${ }^{(3)}$. Slowness was assessed using comfortable walking speed measured with the GAITRite walkway (CIT Systems Inc.). Slowness was defined as a velocity of $<0.76 \mathrm{~m} / \mathrm{s}$ if height was over $173 \mathrm{~cm}$ for males and over $159 \mathrm{~cm}$ for females or $<0.65 \mathrm{~m} / \mathrm{s}$ if participants were shorter ${ }^{(3)}$. Participants were classified as feeling fatigue if they answered 'frequently' or 'mostly' to at least one of the following questions (1) 'I felt that everything I did was an effort' or (2) 'I could not get going'. These questions were adapted from the Center for Epidemiological Studies Depression scale ${ }^{(37)}$. To calculate the overall frailty phenotype, we only included participants with at least three positively or three negatively evaluated symptoms.

\section{Dietary assessment}

A validated self-administrated FFQ consisting of 389 food and beverage items was applied to estimate dietary intake. Participants provided information on the type of food, portion size and preparation method of foods consumed in the last month. Standardised household measures were used to calculate portion sizes and g/d. The Dutch Food Composition Table of 2006 and 2011 was used to calculate average daily intakes of energy, macronutrients and micronutrients. The FFQ was previously validated in two other Dutch populations against a 9-d dietary record $(n \text { 120852) })^{(38)}$ and against a 4-week dietary history $\left(n\right.$ 191) ${ }^{(39)}$. Both validation studies showed that the FFQ is able to adequately rank participants according to their intake (Pearson's correlations for nutrient intakes ranged between $0 \cdot 40$ and 0.86). The Pearson's correlations for total energy intake, 
total dietary protein, plant protein and animal protein were $0.61,0.77,0.61$ and 0.74 , respectively ${ }^{(38)}$.

We calculated total protein intake, animal protein intake and plant-derived protein intake in $\mathrm{g} / \mathrm{d}$. Protein from meat, dairy, fish and eggs were defined as animal derived. Plant-derived proteins included proteins from vegetables, legumes, meat substitutes, nuts and cereals. Furthermore, we calculated for each participant whether the RDA for protein intake was met, defined as $0 \cdot 8 \mathrm{~g} / \mathrm{kg}$ per $\mathrm{BW}^{(33,34)}$ or as $1.2 \mathrm{~g} / \mathrm{kg}$ per $\mathrm{BW}^{(35)}$

As measure of overall diet quality, we calculated adherence to the Dutch dietary guidelines of $2015^{(40)}$ using the Dutch Dietary Guideline Score ${ }^{(41)}$. The score includes fourteen components: high consumption of vegetables $(\geq 200 \mathrm{~g} / \mathrm{d})$, fruit $(\geq 200 \mathrm{~g} / \mathrm{d})$, whole-grain products $(\geq 90 \mathrm{~g} / \mathrm{d})$, legumes $(\geq 135 /$ week), nuts ( $\geq 15 \mathrm{~g} / \mathrm{d})$ and fish $(\geq 100 \mathrm{~g} /$ week $)$; replacement of refined cereal products by whole-grain products $(\geq 50 \%$ of total grains); replacement of butter, hard margarines and hard cooking fats by soft margarines, liquid cooking fats and vegetable oils ( $\geq 50 \%$ of total fats); and limited intake of red meat and processed meat $(<300 \mathrm{~g} /$ week $)$, sugar-containing beverages $(\leq 150 \mathrm{ml} / \mathrm{d})$, alcohol $(\leq 10 \mathrm{~g} / \mathrm{d})$ and salt $(\leq 6 \mathrm{~g} / \mathrm{d})$. For all fourteen components every participant could score 0 (no adherence) or 1 (adherence), resulting in a total sum score with a range from 0 (zero adherence) to 14 (full adherence) ${ }^{(42)}$.

\section{Covariates}

Age was calculated as the years between date of birth and date of the first visit to the research centre. Weight $(\mathrm{kg})$ and height $(\mathrm{cm})$ were measured at the research centre, and BMI $\left(\mathrm{kg} / \mathrm{m}^{2}\right)$ was calculated and categorised as underweight (BMI $<18.5 \mathrm{~kg} / \mathrm{m}^{2}$ ), normal weight $\left(\geq 18.5\right.$ BMI $\left.<25 \mathrm{~kg} / \mathrm{m}^{2}\right)$, overweight $\left(25 \leq \mathrm{BMI}<30 \mathrm{~kg} / \mathrm{m}^{2}\right)$ and obesity $\left(\mathrm{BMI} \geq 30 \mathrm{~kg} / \mathrm{m}^{2}\right)$. Information on cigarette smoking status (never, former or current) was collected through self-report. Education and income were assessed using questionnaires. Education was presented in four categories: primary education with or without a partially completed higher education (primary), lower vocational or lower secondary education (lower), intermediate vocational education or general secondary (intermediate) and higher vocational or university education (higher). Living situation, assessed using a questionnaire, was divided into independent living, sheltered living and nursing home. Presence of comorbidities was defined as having or having had at least one of the following chronic diseases: cancer (past 5 years), CVD, chronic obstructive pulmonary disease or diabetes mellitus. As described above, physical activity was assessed using a self-administered questionnaire. Answers on frequencies and durations were translated into metabolic equivalent of task (MET) values ${ }^{(43)}$. MET values are based on the amount of energy spent on an activity compared with the standard resting metabolic rate $(4.184 \mathrm{~kJ} / \mathrm{kg}$ per h $(1.0 \mathrm{kcal} / \mathrm{kg}$ per h)). For example, sitting has an MET score of $1 \cdot 0-1 \cdot 5$, light-intensity activity (e.g. watching television, working behind a desk) has an MET score of 1.6-2.9 and most sports have MET scores above 6. An average MET value per day was calculated for each participant.

\section{Statistical analysis}

Characteristics of the study population were provided as mean and standard deviations for continuous variables and as percentage for categorical variables, for the full study population and stratified by frailty status (non-frail, pre-frail and frail). Differences in baseline characteristics between the frailty groups were assessed with $\chi^{2}$ statistics (categorical variables) or ANOVA (continuous variables). The Pearson correlation between protein intake, exercise, BMI and frailty was calculated

To assess the association between protein intake and the prevalence of frailty, we used multinomial logistic regression models using the frailty categories as dependent variable (nonfrail as the reference group) and total dietary intake as exposure. First, associations between total protein, plant protein, animal protein and frailty were analysed. We used two different methods to assess this association: nutrient residual models and energy decomposition models ${ }^{(44)}$. For the residual method, we used energy-adjusted residuals of protein intake, and total energy intake was additionally included in the model as a covariate $^{(44)}$. To increase interpretability, the predicted protein intake for the mean energy intake $(8397 \mathrm{~kJ} / \mathrm{d}(2007 \mathrm{kcal} / \mathrm{d}))$ was added to the protein residuals as a constant and protein was analysed per $10 \mathrm{~g} / \mathrm{d}$. We additionally tested if it matters whether protein was consumed at the expense of total carbohydrates or total fat by including these macronutrients one at a time. In these models, the regression coefficient for protein consumption could be interpreted as the association with frailty per $10 \mathrm{~g} / \mathrm{d}$ increase in protein, replacing an isoenergetic amount of other macronutrients. For the energy decomposition $\operatorname{method}^{(44)}$, we included total energy from proteins (per $418.4 \mathrm{~kJ} / \mathrm{d}$ (per $100 \mathrm{kcal} / \mathrm{d}$ )) as the main exposure and energy from all other macronutrients combined as a confounder in the model. The coefficients can be interpreted as the difference in frailty risk per increase in $418.4 \mathrm{~kJ} / \mathrm{d}(100 \mathrm{kcal} / \mathrm{d})$ from protein while intake of other macronutrients is held constant, thus resulting in net higher energy intake. We additionally repeated these analyses for total energy from carbohydrates and total energy from fats. For the second aim, to test for a threshold effect of protein intake on frailty status, we examined whether meeting the current RDA of $0.8 \mathrm{~g} / \mathrm{kg}$ per BW (yes or no) was associated with frailty status. In addition, we used $1.2 \mathrm{~g} / \mathrm{kg}$ per BW as a cut-off of daily allowance.

For each of the aims, we used four levels of confounder adjustment: a basic model (model 1): adjusted for sex, age, cohort and total energy intake. In our main model (model 2) education, BMI, smoking status and diet quality were added in addition to the confounders in model 1. These covariates were entered into the models as they influenced the estimate of protein intake in the basic model with more than $10 \%$. In a third model (model 3), physical activity was added, for which we created a separate model because the overlap in physical activity and frailty could cause over-adjustment. In all models, analyses with plant protein intake were adjusted for animal protein intake and vice versa. Results of the logistic regression were summarised with OR and their corresponding $95 \% \mathrm{CI}$. 
As a sensitivity analysis, we examined effect modification by sex, age, BMI, diet quality and physical activity by adding an interaction term between protein intake and mentioned variables in the main model (model 2), and physical activity and protein intake in model 3 .

We used a multiple imputation procedure ( $n 10$ imputations) to impute the missing values of the covariates. Multicollinearity was checked with the variance inflation factor (VIF) of linear regression analysis. All VIF values (except interaction terms or dummy variables) were lower than 10 , indicating that there was no strong multicollinearity. IBM's SPSS Statistics (version 21) software package was used to analyse the data and values of $P<0.05$ (two-sided) were considered statistically significant.

\section{Results}

\section{Characteristics of the study population}

Of the 2504 participants, 108 were classified as frail, 1309 as pre-frail and 1087 as non-frail. The distribution of sex, age, education, living situation, BMI and physical activity differed significantly between the three frailty groups (Table 1). Furthermore, the average macronutrient intake and physical activity levels of pre-frail and frail participants were lower than those of the non-frail participants (Table 1 ). The average total daily protein intake was $78.9(95 \%$ CI 77.4, 80.3), $76 \cdot 3$ (95\% CI 75.0, 77.7) and $71 \cdot 1(95 \%$ CI $64 \cdot 9,77.4) \mathrm{g} / \mathrm{d}$ for the non-frail, pre-frail and frail participants, respectively, and this corresponds to $15 \cdot 6,15 \cdot 7$ and $15 \cdot 8 \mathrm{E} \%$. In all, $75 \cdot 7,71 \cdot 4$ and $68 \cdot 6 \%$ of the non-frail, pre-frail and frail participants adhered to the RDA of $0.8 \mathrm{~g} / \mathrm{kg}$ per $\mathrm{BW}$. The average score on the Dutch Dietary Guideline Score was 6.8(95\% CI $6.7,6.9)$ and did not significantly differ between the frailty groups (Table 1). Protein intake expressed in $\mathrm{g} / \mathrm{d}$ was univariate associated with hours of physical activity and frailty and expressed as E\% with BMI (Fig. 1).

\section{Protein intake and frailty using nutrient residual models}

In the nutrient residual method, total protein intake was not associated with being either pre-frail or frail (Table 2). Protein intake from vegetable sources was associated with being prefrail in model 2 (OR 1.08, 95\% CI 1.01, 1·15), but not with being frail (Table 2) and was no longer significant after adjusting for physical activity. No association between protein intake from animal sources and frailty status was observed (Table 2). Diet quality did lightly attenuate the association between protein intake and frailty but not significantly. Diet quality itself was not associated with pre-frailty (OR 1·01, 95\% CI 0.97, 1·06, model 2) or frailty (OR $0.95,95 \%$ CI $0.90,1.01$ ). Substitution models in which we examined a higher protein intake at the expense of either fat or carbohydrates did not materially change the association of protein intake and frailty (data not shown).

\section{Protein intake and frailty using energy decomposition models}

When applying the energy decomposition method, no association was observed between higher intakes of energy from total protein with frailty (Table 3). In model 2, higher levels of energy from plant protein were associated with a higher risk to be pre-frail (OR $1 \cdot 15,95 \% \mathrm{CI} 0 \cdot 98,1 \cdot 35)$ and with a lower risk to be frail (OR 0.61, $95 \%$ CI 0.39, 0.97); but after adjusting the models for physical activity in model 3 , these associations were no longer significant (Table 3). In these fully adjusted models (model 3) also energy from fat or energy from carbohydrates were not associated with prevalence of frailty (Table 3). However, we observed that total energy intake (i.e. from any macronutrient source) was significantly associated with lower prevalence of pre-frailty and frailty, even after adjustment for physical activity (Table 3).

\section{Recommended daily allowance of protein intake and frailty}

In the main models (model 2), participants who adhered to the RDA of $0.8 \mathrm{~g}$ protein $/ \mathrm{kg} \mathrm{BW}$ ( $n$ 1831/2504) were not less likely to be frail than participants consuming less protein: OR 1.04 (95\% CI $0.92,1.17)$ for pre-frailty and 1.34 (95\% CI $0.99,1.80)$ for frailty. Also participants who consumed on average at least $1.2 \mathrm{~g}$ protein $/ \mathrm{kg} \mathrm{BW}$ ( $n 652 / 2504)$ were not less likely to be prefrail $(\mathrm{OR}=1.02,95 \% \mathrm{CI} 0.90,1.15)$ or frail $(\mathrm{OR}=1.04,95 \% \mathrm{CI}$ $0.72,1.39)$ than participants who consumed less protein. Additional adjustment by physical activity or diet quality did not alter the results.

\section{Sensitivity analyses}

The interaction terms for physical activity with protein intake, sex and protein intake, age and protein intake and diet quality and protein intake were not significant (all $P$-values $<0.05$ ) in all the models. We did find a significant interaction between BMI and protein intake. When models were stratified in strata of BMI, power became very limited. Although we found somewhat stronger associations between frailty and protein in participants with a BMI $>25 \mathrm{~kg} / \mathrm{m}^{2}$, the overall results remained similar as obtained for the whole group and most significant results disappeared after adjustment for physical activity.

\section{Discussion}

In this population-based study of middle-aged and older adults, we did not observe any consistent association between either relative or absolute protein intake, type of protein and the frailty phenotype. We observed that a higher energy intake was associated with being less frail, but this was not specifically explained by specific macronutrient composition.

Although the association between protein intake and muscular health has been extensively studied, associations with frailty are limited ${ }^{(14,19-22)}$. Our unadjusted results showed that frail participants consumed on average $7 \cdot 8 \mathrm{~g}$ less protein/ $\mathrm{d}$ than non-frail participants. Nevertheless, we observed in our multivariable models that this difference was explained by an overall lower energy intake of frail participants and not by any particular macronutrient. Previous studies on protein intake and frailty showed somewhat conflicting results. One of the first studies to assess the association between protein intake and 
Table 1. Main characteristics of the study population

(Numbers and percentages; mean values and $95 \%$ confidence intervals)

\begin{tabular}{|c|c|c|c|c|c|c|c|c|c|}
\hline \multirow[b]{2}{*}{ Baseline characteristics } & \multicolumn{2}{|c|}{ Full population } & \multicolumn{2}{|c|}{ Non-frail } & \multicolumn{2}{|c|}{ Pre-frail } & \multicolumn{2}{|c|}{ Frail } & \multirow[b]{2}{*}{$P^{\star}$} \\
\hline & $n$ & $\%$ & $n$ & $\%$ & $n$ & $\%$ & $n$ & $\%$ & \\
\hline$n$ & \multicolumn{2}{|c|}{2504} & \multicolumn{2}{|c|}{1087} & \multicolumn{2}{|c|}{1309} & \multicolumn{2}{|c|}{108} & \multirow{4}{*}{$<0.001$} \\
\hline \multicolumn{9}{|l|}{ Sex } & \\
\hline Males & 1109 & $44 \cdot 3$ & 525 & 48 & 547 & 42 & 37 & 34 & \\
\hline Females & 1395 & 55.7 & 562 & 52 & 762 & 58 & 71 & 66 & \\
\hline Age (years) & & & & & & & & & $<0.001$ \\
\hline Mean & \multicolumn{2}{|c|}{74.9} & \multicolumn{2}{|c|}{73.3} & & & & & \\
\hline $95 \% \mathrm{Cl}$ & & & & 3.6 & 75 & & & 31.8 & \\
\hline Education & & & & & & & & & 0.001 \\
\hline Primary education & 155 & $6 \cdot 3$ & 50 & 4.6 & 96 & $7 \cdot 3$ & 13 & 12 & \\
\hline Lower education & 1057 & 43 & 454 & 42 & 567 & 43 & 52 & 48 & \\
\hline Intermediate education & 815 & 33 & 368 & 34 & 440 & 34 & 30 & 28 & \\
\hline Higher education & 425 & 17 & 215 & 20 & 203 & 16 & 13 & 12 & \\
\hline Living situation & & & & & & & & & 0.024 \\
\hline Independent & 2243 & 90 & 996 & 92 & 1159 & 89 & 89 & 82 & \\
\hline Sheltered living & 251 & 10 & 88 & $8 \cdot 1$ & 144 & 11 & 19 & 18 & \\
\hline Nursing home & 4 & 0.2 & 2 & 0.2 & 2 & 0.2 & 0 & 0 & \\
\hline Smoking & & & & & & & & & 0.62 \\
\hline Never smoker & 799 & 32 & 336 & 31 & 429 & 33 & 34 & 31 & \\
\hline Former smoker & 1416 & 57 & 633 & 58 & 721 & 55 & 62 & 57 & \\
\hline Current smoker & 291 & 12 & 118 & 11 & 159 & 12 & 12 & 11 & \\
\hline Weight status & & & & & & & & & $<0.001$ \\
\hline Weight $(\mathrm{kg})$ & & & & & & & & & \\
\hline Mean & & & & & & & & & \\
\hline $95 \% \mathrm{Cl}$ & & & & $8 \cdot 7$ & 75 & & & $75 \cdot 2$ & \\
\hline Underweight $\left(\mathrm{BMl}<18.5 \mathrm{~kg} / \mathrm{m}^{2}\right)$ & 10 & 0.4 & 2 & 0.2 & 7 & 0.5 & 1 & 0.9 & \\
\hline Normal weight $\left(18.5 \mathrm{BMl}<25 \mathrm{~kg} / \mathrm{m}^{2}\right)$ & 712 & 28 & 324 & 30 & 347 & 27 & 41 & 38 & \\
\hline Overweight $\left(25 \mathrm{BMI}<30 \mathrm{~kg} / \mathrm{m}^{2}\right)$ & 1222 & 50 & 558 & 51 & 622 & 68 & 42 & 39 & \\
\hline Obese $\left(\mathrm{BMI} \geq 30 \mathrm{~kg} / \mathrm{m}^{2}\right)$ & 560 & 22 & 203 & 19 & 333 & 25 & 24 & 22 & \\
\hline Physical activity (MET score) & & & & & & & & & $<0.001$ \\
\hline Mean & & & & & & & & & \\
\hline $95 \% \mathrm{Cl}$ & & & $58 \cdot \varepsilon$ & 5.68 & $49 \cdot 6$ & 5.59 & & $12 \cdot 80$ & \\
\hline Dietary intake & & & & & & & & & \\
\hline Energy intake $(\mathrm{kJ} / \mathrm{d})$ & & & & & & & & & $<0.001$ \\
\hline Mean & & & & & & & & & \\
\hline $95 \% \mathrm{Cl}$ & & & 85 & 845 & 817 & 473 & & 3401 & \\
\hline Energy intake $(\mathrm{kcal} / \mathrm{d})$ & & & & & & & & & $<0.001$ \\
\hline Mean & & & & & & & & & \\
\hline $95 \% \mathrm{Cl}$ & & & & 114 & 195 & 025 & & 2008 & \\
\hline Carbohydrate intake $(\mathrm{g} / \mathrm{d})$ & & & & & & & & & $<0.001$ \\
\hline Mean & & & & & & & & & \\
\hline $95 \% \mathrm{Cl}$ & 223 & & 227 & 37.8 & 221. & 30.5 & & $228 \cdot 0$ & \\
\hline Fat intake (g/d) & & & & & & & & & 0.004 \\
\hline Mean & & & & & & & & & \\
\hline $95 \% \mathrm{Cl}$ & & & & $6 \cdot 8$ & 69. & & & 76.5 & \\
\hline Protein $(\mathrm{g} / \mathrm{d})$ & & & & & & & & & $<0.001$ \\
\hline Mean & & & & & & & & & \\
\hline $95 \% \mathrm{Cl}$ & & & & 0.3 & 75 & & & 77.4 & \\
\hline Plant protein $(\mathrm{g} / \mathrm{d})$ & & & & & & & & & $<0.001$ \\
\hline Mean & & & & & & & & & \\
\hline $95 \% \mathrm{Cl}$ & & & & 1.7 & 29. & & & 29.9 & \\
\hline Animal protein intake $(\mathrm{g} / \mathrm{d})$ & & & & & & & & & 0.011 \\
\hline Mean & & & & & & & & & \\
\hline $95 \% \mathrm{Cl}$ & & & & $9 \cdot 0$ & & & & 48.9 & \\
\hline Adherence to protein RDA $0.8 \mathrm{~g} / \mathrm{kg}$ per BW & 1831 & 73.1 & 823 & $75 \cdot 7$ & 934 & $71 \cdot 4$ & 74 & 68.5 & $<0.001$ \\
\hline Adherence protein RDA $1.2 \mathrm{~g} / \mathrm{kg}$ per BW & 652 & 26.0 & 303 & $27 \cdot 9$ & 324 & $24 \cdot 8$ & 25 & $23 \cdot 1$ & 0.031 \\
\hline Dietary guidelines score & & & & & & & & & 0.41 \\
\hline Mean & & & & & & & & & \\
\hline $95 \% \mathrm{Cl}$ & & & & 94 & $6 \cdot 7$ & & & 38 & \\
\hline
\end{tabular}

MET, metabolic equivalent of task; RDA, recommended daily allowance; BW, body weight.

* $P$-values for differences in characteristics between the three frailty groups, assessed with $\chi^{2}$ tests for categorical variables or ANOVA for continuous variables.

frailty was performed by Bartali et al. ${ }^{(45)}$, among 802 Italian older persons (aged 65 years and over). They observed that subjects in the lowest quintile of protein intake (men $<66 \mathrm{~g}$; women $<55 \mathrm{~g}$ ) were more likely to be frail in energy-adjusted models. However, they only adjusted for energy by including $\mathrm{kJ}$ in the model as a dichotomous variable, thus results may still 


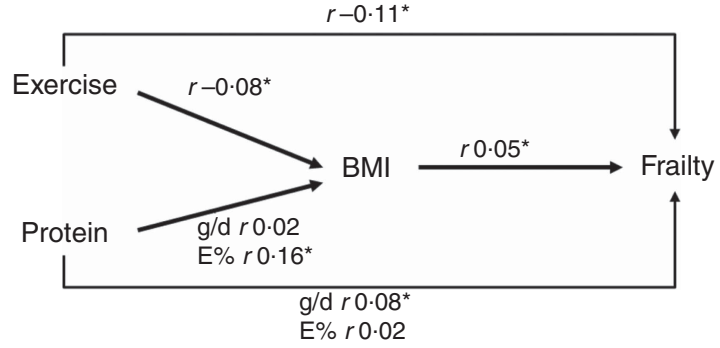

Fig. 1. Suggested directions, associations present Pearson correlation coefficients. ${ }^{*}$ Significant associations $(P<0.05)$.

partly be explained by energy intake. A later study observed that protein intake of at least $1 \mathrm{~g} / \mathrm{kg}$ per BW was associated, adjusted for total energy intake (continuous), with lower odds to be frail and did not find an association between total energy and frailty ${ }^{(46)}$. The frail sample was relatively small $(n 55)$ and protein intake was estimated using one $24 \mathrm{~h}$ recall, providing a limited estimate of habitual diet. Kobayashi et al. ${ }^{(47)}$ also found an inverse association between total protein intake (in quintiles) and frailty in Japanese women adjusted for total energy intake but not for physical activity. We could not replicate these results. In line with our findings, Shikany et al. ${ }^{(31)}$ did not observe an association between protein intake in quintiles and frailty in energy-adjusted models and Bollwein et al. ${ }^{(48)}$, observed no difference in frailty status between subjects in higher than subjects in the lowest quartile of energy-adjusted protein intake.

The contradictory results could be explained by the lack of adjustments for energy and/or physical activity in most previous studies. Indeed, most studies that do adjust for energy intake observed that the effect estimates became smaller ${ }^{(45,46)}$. We found that a higher energy intake was associated with being less frail, which was not specifically explained by protein intake or any other macronutrient. The overall association between frailty and energy can be explained by several factors. First, frail participants are more likely to have lower general health status that can be associated with lower appetite and/or other eating disabilities (e.g. difficulties with chewing). Second, frail participants are less physical active, thereby they need less energy and are also likely to consume less kJ. Although we adjusted models for physical activity to rule out that the association is completely explained by physical activity, there may be some residual confounding. Third, the component of energy loss in frail participants is likely to be associated with low energy intake. Our finding was contradictory to the results of Rahi et $a l .{ }^{(46)}$ who concluded that not higher energy intake but higher protein consumption was associated with a lower frailty prevalence. Because our study population was relatively healthy, consumed high levels of protein and were physically active, we might have missed a possible protective effect of protein intake in less vital subjects, as it has been found that protein supplementation is mainly beneficial in less healthy individuals or in those consuming little dietary protein ${ }^{(49-51)}$. In addition, BMI could play an important role in the association between protein intake and frailty. Sarcopenic obesity is a serious condition, in which people have too much fat but too little muscle mass ${ }^{(52)}$. It could be that in this specific subpopulation protein intake does play an important role. Future research with larger populations should focus on better understanding the role of BMI and protein in the development of frailty and sarcopenia ${ }^{(53)}$.

It has been implied that not only total protein intake but the protein source is important to prevent frailty, with stronger effects for protein from animal food sources because they are generally richer in essential amino acids such as leucine ${ }^{(27,28)}$. Contradictory to this theory and in line with others ${ }^{(47,54)}$, we did not observe differences between animal and plant protein. It could be that a high amount of animal protein in theory has a beneficial effect on muscle health, but because it is also associated with a less optimal dietary pattern (e.g. high in red meat and fats), the beneficial effect on frailty is diminished. A high intake of plant protein (e.g. high in legumes, lentils) is generally associated with a more optimal dietary pattern that could beneficially affect frailty. Indeed, although evidence is scarce, studies suggest that dietary patterns influence frailty status $^{(12,31,55,56)}$.

Overall, our cross-sectional findings suggest that in a population with a relatively healthy diet, high protein intake and high physical activity, total energy intake is more important than macronutrient content in the relation with frailty. Nevertheless, there is a complex interaction between physical activity, energy and protein intake, BMI and muscle preservation. Optimising dietary protein could help in the prevention of frailty but other important topics including appetite control, physical activity, BMI, energy balance and dietary quality should be taken into consideration as well. Future efforts should take all these topics into account to better understand their interactions and pathways $^{(57)}$.

The major strengths of our study are the population-based setting, the high quality and detail of the measurements and the use of different statistical methods to consider the possible modifying or confounding effect of total energy and dietary quality. However, there are also several limitations that need to be considered. First, our analyses are cross-sectional which makes the assessment of temporal direction and causality between protein intake and frailty impossible. It could be that due to reversed causation we did not find an association, as frail older adults may have adapted their dietary behaviour towards a more protein-dense pattern. In the subgroup without chronic disease, we did not find a preventive effect of protein either. Second, for some results, confidence intervals around the effect estimates were rather large, probably caused by a low number of cases in the subgroups. This could have resulted in a type 2 error and failure to detect significant effects. Third, we used slightly modified criteria of the phenotypic criteria. It was unknown whether weight loss was intended or unintended, and we used different questionnaires to estimate the physical activity and the exhaustion criterion. This could have led to differences in the frailty prevalence ${ }^{(58)}$. In addition to the phenotype of frailty, there are several other, broader definitions of frailty (e.g. the frailty index or the Tilburg Frailty Indicator). In the current study, we did not evaluate whether and how protein intake could influence frailty defined by other operationalizations. Fourth, we used self-reported dietary intake using a 
Table 2. Association between protein intake and pre-frailty and frailty, using the nutrient residual method, multinomial regression analyses*

(Odds ratios and $95 \%$ confidence intervals per $10 \mathrm{~g}$ protein increase per d)

\begin{tabular}{|c|c|c|c|c|}
\hline & \multicolumn{2}{|c|}{ Pre-frail } & \multicolumn{2}{|c|}{ Frail } \\
\hline & OR & $95 \% \mathrm{Cl}$ & OR & $95 \% \mathrm{Cl}$ \\
\hline \multicolumn{5}{|c|}{ Total protein intake (per $10 \mathrm{~g} / \mathrm{d}$ ) } \\
\hline Model $1 \dagger$ & 1.03 & $0.97,1.09$ & 1.07 & $0.92,1.25$ \\
\hline Model $2 \ddagger$ & 1.01 & $0.98,1.04$ & 1.06 & $0.98,1.15$ \\
\hline Model 3§ & 1.02 & $0.96,1.08$ & 1.07 & $0.92,1.24$ \\
\hline \multicolumn{5}{|c|}{ Plant protein intake (per $10 \mathrm{~g} / \mathrm{d}$ ) } \\
\hline Model $1 \dagger$ & $1 \cdot 10$ & $0.97,1.24$ & 0.85 & $0.60,1.22$ \\
\hline Model $2 \ddagger$ & 1.08 & $1.00,1.15$ & 0.87 & $0.71,1.07$ \\
\hline Model $3 \S$ & 1.08 & $0.94,1.24$ & 0.88 & $0.59,1.30$ \\
\hline \multicolumn{5}{|c|}{ Animal protein intake (per $10 \mathrm{~g} / \mathrm{d}$ ) } \\
\hline Model $1 t$ & 1.02 & $0.97,1.08$ & 1.08 & $0.94,1.25$ \\
\hline Model $2 \ddagger$ & 1.01 & $0.98,1.04$ & 1.06 & $0.99,1.15$ \\
\hline Model $3 \S$ & 1.01 & $0.95,1.07$ & 1.07 & $0.93,1.24$ \\
\hline
\end{tabular}

${ }^{*}$ Reference category: non-frail.

† Model 1 adjusted for age, sex and total energy intake (kJ). Models with plant protein intake are additionally adjusted for animal protein intake and vice versa.

‡ Model 2 adjusted for age, sex and total energy intake (kJ), smoking status, education, diet quality and BMI.

$\S$ Model 3 adjusted for age, sex and total energy intake (kJ), smoking status, education, diet quality and BMI and physical activity.

Table 3. Association between protein intake and pre-frailty and frailty, using the energy partition model, multinomial logistic regression analyses

(Odds ratios and $95 \%$ confidence intervals per $418.4 \mathrm{~kJ}$ protein $/ \mathrm{d}(100 \mathrm{kcal}$ protein $/ \mathrm{d})$ )

\begin{tabular}{|c|c|c|c|c|}
\hline & \multicolumn{2}{|c|}{ Pre-frail } & \multicolumn{2}{|c|}{ Frail } \\
\hline & OR & $95 \% \mathrm{Cl}$ & OR & $95 \% \mathrm{Cl}$ \\
\hline \multicolumn{5}{|c|}{ Energy for any source (per $418.4 \mathrm{~kJ}$ (per $100 \mathrm{kcal})$ ) } \\
\hline Model $1 \dagger$ & $0.98^{*}$ & $0.97,0.99$ & $0.95^{\star}$ & $0.92,0.98$ \\
\hline Model $2 \ddagger$ & $0.98^{\star}$ & $0.98,0.99$ & $0.95^{\star}$ & $0.93,0.97$ \\
\hline Model $3 \S$ & 0.99 & $0.97,1.00$ & $0.95^{\star}$ & $0.92,0.99$ \\
\hline \multicolumn{5}{|c|}{ Energy from protein (per $418.4 \mathrm{~kJ}$ (per $100 \mathrm{kcal}))$} \\
\hline Model $1 \dagger$ & 1.04 & $0.92,1.18$ & $1 \cdot 11$ & $0.80,1.54$ \\
\hline Model $2 \ddagger$ & 1.01 & $0.95,1.08$ & 1.09 & $0.92,1.29$ \\
\hline Model $3 \S$ & 1.02 & $0.90,1.16$ & $1 \cdot 11$ & $0.80,1.54$ \\
\hline \multicolumn{5}{|c|}{ Energy from plant protein (per $418.4 \mathrm{~kJ}$ (per $100 \mathrm{kcal})$ ) } \\
\hline Model 1† & $1 \cdot 18$ & $0.89,1.56$ & 0.57 & $0.26,1.28$ \\
\hline Model $2 \ddagger$ & $1 \cdot 15^{\star}$ & $0.98,1.35$ & $0.61^{*}$ & $0.39,0.97$ \\
\hline Model $3 \S$ & 1.17 & $0.85,1.59$ & 0.62 & $0.25,1.50$ \\
\hline \multicolumn{5}{|c|}{ Energy from animal protein (per $418.4 \mathrm{~kJ}$ (per $100 \mathrm{kcal})$ ) } \\
\hline Model $1 \dagger$ & 1.00 & $0.88,1.14$ & 1.19 & $0.87,1.63$ \\
\hline Model $2 \ddagger$ & 0.98 & $0.92,1.05$ & $1 \cdot 14$ & $0.97,1.34$ \\
\hline Model $3 \S$ & 0.99 & $0.87,1.13$ & 1.16 & $0.85,1.60$ \\
\hline \multicolumn{5}{|c|}{ Energy from carbohydrates (per $418.4 \mathrm{~kJ}$ (per $100 \mathrm{kcal})$ ) } \\
\hline Model $1 \dagger$ & 0.99 & $0.96,1.02$ & 0.93 & $0.86,1.01$ \\
\hline Model $2 \ddagger$ & 1.00 & $0.97,1.02$ & $0.93^{*}$ & $0.89,0.97$ \\
\hline Model $3 \S$ & 1.00 & $0.97,1.03$ & 0.94 & $0.86,1.02$ \\
\hline \multicolumn{5}{|c|}{ Energy from fats (per $418.4 \mathrm{~kJ}$ (per $100 \mathrm{kcal})$ ) } \\
\hline Model 1† & 0.99 & $0.96,1.03$ & 1.01 & $0.94,1.09$ \\
\hline Model $2 \ddagger$ & 1.00 & $0.98,1.01$ & 1.01 & $0.94,1.09$ \\
\hline Model $3 \S$ & 1.00 & $0.96,1.03$ & 1.01 & $0.94,1.09$ \\
\hline
\end{tabular}

* $P<0.05$.

† Model 1 adjusted for age, sex and total energy intake $(\mathrm{kJ})$ from other macronutrient sources. Models with plant protein intake are additionally adjusted for animal protein intake and vice versa.

‡ Model 2 adjusted for age, sex and total energy intake (kJ) from other macronutrient sources, smoking status, education, diet quality and BMI.

$\S$ Model 3 adjusted for age, sex and total energy intake $(\mathrm{kJ})$ from other macronutrient sources, smoking status, education, diet quality and BMI and physical activity.

validated FFQ. Although an FFQ is an appropriate method to rank subjects according to their habitual diet, the use of an FFQ could lead to underreported absolute energy and protein intake ${ }^{(31)}$. Indeed the reported average energy intake of our population seems low, considering the relatively high percentage of overweight and obese participants. It has been suggested that using such uncalibrated measures could underestimate the association between protein intake and frailty ${ }^{(54)}$. Furthermore, the FFQ cannot be used to evaluate the distribution of protein intake over the day, which has been suggested to be important to prevent frailty in the addition of total amount $^{(48)}$. Last, we applied two cut-off values for protein 
intake. Nevertheless, there is an ongoing debate on protein requirements and different requirements have been suggested $^{(59-61)}$. In conclusion, our results suggest that the overall dietary energy intake, rather than protein intake or intake of other macronutrients, is inversely associated with frailty. It is therefore important to further study the incidence of frailty over time and how this relates to dietary energy intake, protein intake and protein sources. Future studies should examine how sufficient energy intake may prevent frailty and whether specific groups may need particular dietary interventions for preventing frailty, for example, in older adults who do not consume sufficient proteins, have a low physical activity level or already have a low muscle mass.

\section{Acknowledgements}

The authors gratefully acknowledge the contribution of the participants of the RS, research assistants, the general practitioners, hospitals and pharmacies in Rotterdam.

The RS is supported by the Erasmus MC and Erasmus University Rotterdam, the Netherlands Organisation for Scientific Research (NWO), the Netherlands Organisation for Health Research and Development (ZonMw), the Research Institute for Diseases in the Elderly, the Netherlands Genomics Initiative, the Ministry of Education, Culture and Science, the Ministry of Health Welfare and Sport, the European. J. D. S., T. V., J. C. K.-d. J. and O. H. F. work in Erasmus AGE, a centre for ageing research across the life course funded by Nestlé Nutrition (Nestec Ltd) and Metagenics Inc. The authors took the final responsibility of the design and conduct of the study, collection, management, analysis and interpretation of the data and preparation, review or approval of the manuscript. F. R. received a grant from the Netherlands Organization for Health Research and Development ZonMw VIDI 016.136.367.

J. D. S. and T. V. designed the research; J. D. S., T. V., J. C. K.-d. J., K. T. and L. L. conducted the research; J. D. S., T. V., F. R., B. S., G. B., L. L. and O. H. F. provided essential materials; J. D. S. and T. V. analysed the data or performed statistical analysis; J. D. S. and T. V. wrote the paper; J. D. S., T. V. and O. H. F. took the primary responsibility of the final content; J. D. S., T. V., J. C. K.-d. J., K. T., F. R., B. S., G. B., L. L. and O. H. F. provided intellectual content to the paper; all authors read and approved the final manuscript.

The authors declare that there are no conflicts of interest.

\section{References}

1. Clegg A, Young J, Iliffe S, et al. (2013) Frailty in elderly people. Lancet 381, 752-762.

2. Morley JE, Vellas B, van Kan GA, et al. (2013) Frailty consensus: a call to action. J Am Med Dir Assoc 14, 392-397.

3. Fried LP, Tangen CM, Walston J, et al. (2001) Frailty in older adults: evidence for a phenotype. J Gerontol A Biol Sci Med Sci 56, M146-M156.

4. Shamliyan T, Talley KM, Ramakrishnan R, et al. (2013) Association of frailty with survival: a systematic literature review. Ageing Res Rev 12, 719-736.

5. Baldwin MR, Reid MC, Westlake AA, et al. (2014) The feasibility of measuring frailty to predict disability and mortality in older medical intensive care unit survivors. J Crit Care 29, 401-408.

6. Chang SF \& Lin PL (2015) Frail phenotype and mortality prediction: a systematic review and meta-analysis of prospective cohort studies. Int J Nurs Stud 52, 1362-1374.

7. Kojima G, Iliffe S, Jivraj S, et al. (2016) Association between frailty and quality of life among community-dwelling older people: a systematic review and meta-analysis. J Epidemiol Community Health 70, 716-721.

8. Lahousse L, Ziere G, Verlinden VJ, et al. (2016) Risk of frailty in elderly with COPD: a population-based study. J Gerontol $A$ Biol Sci Med Sci 71, 689-695.

9. Collard RM, Boter H, Schoevers RA, et al. (2012) Prevalence of frailty in community-dwelling older persons: a systematic review. J Am Geriatr Soc 60, 1487-1492.

10. Lahousse L, Maes B, Ziere G, et al. (2014) Adverse outcomes of frailty in the elderly: the Rotterdam Study. Eur J Epidemiol 29, 419-427.

11. Kelaiditi E, Guyonnet S \& Cesari M (2015) Is nutrition important to postpone frailty? Curr Opin Clin Nutr Metab Care 18, 37-42.

12. Bollwein J, Diekmann R, Kaiser MJ, et al. (2013) Dietary quality is related to frailty in community-dwelling older adults. J Gerontol A Biol Sci Med Sci 68, 483-489.

13. Bonnefoy M, Berrut G, Lesourd B, et al. (2015) Frailty and nutrition: searching for evidence. J Nutr Health Aging 19, 250-257.

14. Artaza-Artabe I, Saez-Lopez P, Sanchez-Hernandez N, et al. (2016) The relationship between nutrition and frailty: effects of protein intake, nutritional supplementation, vitamin D and exercise on muscle metabolism in the elderly. A systematic review. Maturitas 93, 89-99.

15. Cesari M, Landi F, Vellas B, et al. (2014) Sarcopenia and physical frailty: two sides of the same coin. Front Aging Neurosci 6, 192

16. Keevil VL \& Romero-Ortuno R (2015) Ageing well: a review of sarcopenia and frailty. Proc Nutr Soc 74, 337-347.

17. Beasley JM, Shikany JM \& Thomson CA (2013) The role of dietary protein intake in the prevention of sarcopenia of aging. Nutr Clin Pract 28, 684-690.

18. Cermak NM, Res PT, de Groot LC, et al. (2012) Protein supplementation augments the adaptive response of skeletal muscle to resistance-type exercise training: a meta-analysis. Am J Clin Nutr 96, 1454-1464.

19. Nanri H, Yamada Y, Yoshida T, et al. (2018) Sex difference in the association between protein intake and frailty: assessed using the kihon checklist indexes among older adults. $J \mathrm{Am}$ Med Dir Assoc 19, 801-805.

20. Lorenzo-Lopez L, Maseda A, de Labra C, et al. (2017) Nutritional determinants of frailty in older adults: a systematic review. BMC Geriatr 17, 108-121.

21. Kobayashi S, Suga H, Sasaki S, et al. (2017) Diet with a combination of high protein and high total antioxidant capacity is strongly associated with low prevalence of frailty among old Japanese women: a multicenter cross-sectional study. Nutr J 16, 29.

22. Yannakoulia M, Ntanasi E, Anastasiou CA, et al. (2017) Frailty and nutrition: from epidemiological and clinical evidence to potential mechanisms. Metabolism 68, 64-76.

23. Tribess S, Virtuoso Junior JS \& Oliveira RJ (2012) Physical activity as a predictor of absence of frailty in the elderly. Rev Assoc Med Bras 58, 341-347.

24. Blodgett J, Theou O, Kirkland S, et al. (2015) The association between sedentary behaviour, moderate-vigorous physical activity and frailty in NHANES cohorts. Maturitas 80, 187-191.

25. Tieland M, Dirks ML, van der Zwaluw N, et al. (2012) Protein supplementation increases muscle mass gain during 
prolonged resistance-type exercise training in frail elderly people: a randomized, double-blind, placebo-controlled trial. J Am Med Dir Assoc 13, 713-719.

26. Lana A, Rodriguez-Artalejo F \& Lopez-Garcia E (2015) Dairy consumption and risk of frailty in older adults: a prospective cohort study. J Am Geriatr Soc 63, 1852-1860.

27. Lord C, Chaput JP, Aubertin-Leheudre M, et al. (2007) Dietary animal protein intake: association with muscle mass index in older women. J Nutr Health Aging 11, 383-387.

28. Volpi E, Kobayashi H, Sheffield-Moore M, et al. (2003) Essential amino acids are primarily responsible for the amino acid stimulation of muscle protein anabolism in healthy elderly adults. Am J Clin Nutr 78, 250-258.

29. Guenther PM, Casavale KO, Reedy J, et al. (2013) Update of the healthy eating index: HEI-2010. J Acad Nutr Diet 113, 569-580.

30. Phillips SM, Fulgoni VL 3rd, Heaney RP, et al. (2015) Commonly consumed protein foods contribute to nutrient intake, diet quality, and nutrient adequacy. Am J Clin Nutr 101, 1346S-1352S

31. Shikany JM, Barrett-Connor E, Ensrud KE, et al. (2014) Macronutrients, diet quality, and frailty in older men. J Gerontol A Biol Sci Med Sci 69, 695-701.

32. Morley JE (2012) Do frail older persons need more protein? J Am Med Dir Assoc 13, 667-668.

33. Dideriksen K, Reitelseder S \& Holm L (2013) Influence of amino acids, dietary protein, and physical activity on muscle mass development in humans. Nutrients 5, 852-876.

34. Rand WM, Pellett PL \& Young VR (2003) Meta-analysis of nitrogen balance studies for estimating protein requirements in healthy adults. Am J Clin Nutr 77, 109-127.

35. Bauer J, Biolo G, Cederholm T, et al. (2013) Evidence-based recommendations for optimal dietary protein intake in older people: a position paper from the PROT-AGE Study Group. J Am Med Dir Assoc 14, 542-559.

36. Hofman A, Brusselle GG, Darwish Murad S, et al. (2015) The Rotterdam Study: 2016 objectives and design update. Eur J Epidemiol 30, 661-708.

37. Radloff LS (1977) The CES-D scale: a self-report depression scale for research in the general population. Appl Psychol Meas 1, 385-401.

38. Goldbohm RA, van den Brandt PA, Brants HA, et al. (1994) Validation of a dietary questionnaire used in a large-scale prospective cohort study on diet and cancer. Eur J Clin Nutr 48, 253-265.

39. Feunekes GI, Van Staveren WA, De Vries JH, et al. (1993) Relative and biomarker-based validity of a food-frequency questionnaire estimating intake of fats and cholesterol. $\mathrm{Am} \mathrm{J}$ Clin Nutr 58, 489-496.

40. Dutch Health Council (Gezondheidsraad) (2015) Dutch Dietary Guidelines 2015 (Richtlijnen goede voeding 2015). The Hague: Dutch Health Council.

41. Voortman T, Kiefte-de Jong JC, Ikram MA, et al. (2017) Adherence to the 2015 Dutch dietary guidelines and risk of non-communicable diseases and mortality in the Rotterdam Study. Eur J Epidemiol 32, 993-1005.

42. Voortman T, Kiefte-de Jong JC, Ikram MA, et al. (Submitted) Associations of adherence to the Dutch dietary guidelines with incidence of non-communicable diseases and mortality in the Rotterdam Study.

43. Ainsworth BE, Haskell WL, Herrmann SD, et al. (2011) 2011 Compendium of physical activities: a second update of codes and MET values. Med Sci Sports Exerc 43, 1575-1581.

44. Willett WC, Howe GR \& Kushi LH (1997) Adjustment for total energy intake in epidemiologic studies. Am J Clin Nutr $\mathbf{6 5}$, 1220S-1228S (discussion 1229S-1231S).
45. Bartali B, Frongillo EA, Bandinelli S, et al. (2006) Low nutrient intake is an essential component of frailty in older persons. J Gerontol A Biol Sci Med Sci 61, 589-593.

46. Rahi B, Colombet Z, Gonzalez-Colaco Harmand $\mathrm{M}$, et al. (2016) Higher protein but not energy intake is associated with a lower prevalence of frailty among community-dwelling older adults in the French Three-City Cohort. J Am Med Dir Assoc 17, 672.e7-672.e11.

47. Kobayashi S, Asakura K, Suga H, et al. (2013) High protein intake is associated with low prevalence of frailty among old Japanese women: a multicenter cross-sectional study. Nutr J 12, 164.

48. Bollwein J, Diekmann R, Kaiser MJ, et al. (2013) Distribution but not amount of protein intake is associated with frailty: a cross-sectional investigation in the region of Nurnberg. Nutr J 12, 109.

49. Smoliner C, Norman K, Scheufele R, et al. (2008) Effects of food fortification on nutritional and functional status in frail elderly nursing home residents at risk of malnutrition. Nutrition 24, 1139-1144.

50. Milne AC, Avenell A \& Potter J (2006) Meta-analysis: protein and energy supplementation in older people. Ann Intern Med 144, 37-48.

51. Thomas DK, Quinn MA, Saunders DH, et al. (2016) Protein supplementation does not significantly augment the effects of resistance exercise training in older adults: a systematic review. J Am Med Dir Assoc 17, 959.e1-959.e9.

52. Batsis JA \& Villareal DT (2018) Sarcopenic obesity in older adults: aetiology, epidemiology and treatment strategies. Nat Rev Endocrinol 14, 513-537.

53. Bendtsen LQ, Lorenzen JK, Bendsen NT, et al. (2013) Effect of dairy proteins on appetite, energy expenditure, body weight, and composition: a review of the evidence from controlled clinical trials. Adv Nutr 4, 418-438.

54. Beasley JM, LaCroix AZ, Neuhouser ML, et al. (2010) Protein intake and incident frailty in the Women's Health Initiative observational study. J Am Geriatr Soc $\mathbf{5 8}$, 1063-1071.

55. Talegawkar SA, Bandinelli S, Bandeen-Roche $\mathrm{K}$, et al. (2012) A higher adherence to a Mediterranean-style diet is inversely associated with the development of frailty in community-dwelling elderly men and women. J Nutr $\mathbf{1 4 2}$, 2161-2166

56. Leon-Munoz LM, Guallar-Castillon P, Lopez-Garcia E, et al. (2014) Mediterranean diet and risk of frailty in communitydwelling older adults. J Am Med Dir Assoc 15, 899-903.

57. Paddon-Jones D \& Leidy H (2014) Dietary protein and muscle in older persons. Curr Opin Clin Nutr Metab Care 17, 5-11.

58. Theou O, Cann L, Blodgett J, et al. (2015) Modifications to the frailty phenotype criteria: systematic review of the current literature and investigation of 262 frailty phenotypes in the Survey of Health, Ageing, and Retirement in Europe. Ageing Res Rev 21, 78-94.

59. Rafii M, Chapman K, Elango R, et al. (2016) Dietary protein requirement of men $>65$ years old determined by the indicator amino acid oxidation technique is higher than the current estimated average requirement. J Nutr.

60. Trumbo P, Schlicker S, Yates AA, et al. (2002) Dietary reference intakes for energy, carbohydrate, fiber, fat, fatty acids, cholesterol, protein and amino acids. J Am Diet Assoc 102, $1621-1630$

61. Rafii M, Chapman K, Owens J, et al. (2015) Dietary protein requirement of female adults $>65$ years determined by the indicator amino acid oxidation technique is higher than current recommendations. J Nutr 145, 18-24. 